\title{
Looking over the rim: algorithms for cheminformatics from computer scientists
}

\author{
Thorsten Meinl ${ }^{1 *}$, Bernd Wiswedel ${ }^{1}$, Michael R Berthold ${ }^{1,2}$ \\ From 9th German Conference on Chemoinformatics \\ Fulda, Germany. 10-12 November 2013
}

In recent years a number of methods were invented in the data mining/machine learning field that have received little attention in the cheminformatics world even though they offer interesting properties for these types of applications as well - even compared to some similar algorithms published primarily in the cheminformatics space. In this talk we want to highlight three of these algorithms/approaches. The first is MoSS [1], a frequent subgraph miner that can not only be used to find common substructures in a set of molecules but is also able to compute the MCSS very fast and has some extension especially suited for molecules. The second presented approach deals with the problem of finding diverse subsets of molecules [2]. Quite interestingly, not only finding a diverse subset can be a challenging task but already the definition of diversity is not as straight-forward as it seems at the first glance. The third algorithm goes along the same lines but tries to find similar molecules by looking at their properties from so-called parallel universes[3]. Each universe contains a set of related properties and partial predictive models are built in each universe separately. Through interactive model construction, e.g. by so-called Neighbourgrams, the models from one universe can aid the construction of a models in other universes.

\section{Authors' details \\ ${ }^{1}$ KNIME.com AG, Zurich, 8005, Switzerland. ${ }^{2}$ University of Konstanz, Konstanz, 78457, Germany.}

\section{Published: 11 March 2014}

\section{References}

1. Borgelt C: Canonical Forms for Frequent Graph Mining. Proc. 30th Annual Conf. of the German Classification Society (GfKl 2006, Berlin, Germany) Springer-Verlag, Heidelberg, Germany; 2006, 337-349.

* Correspondence: thorsten.meinl@knime.com

${ }^{1}$ KNIME.com AG, Zurich, 8005, Switzerland

Full list of author information is available at the end of the article
2. Meinl T, Ostermann C, Berthold MR: Maximum-Score Diversity Selection for Early Drug Discovery. J Chem Inf Model 2011, 51:237-247.

3. Wiswdel B, Berthold MR: Supervised Learning in Parallel Universes using Neighborgrams. In Proceedings of the 10th International Symposium on Intelligent Data Analysis, Series Lecture Notes in Computer Science (LNCS). Volume 7014. Springer-Verlag, Heidelberg, Germany; 2011:388-400.

doi:10.1186/1758-2946-6-S1-013

Cite this article as: Meinl et al:: Looking over the rim: algorithms for cheminformatics from computer scientists. Journal of Cheminformatics 2014 6(Suppl 1):013.

\section{Publish with ChemistryCentral and every scientist can read your work free of charge \\ "Open access provides opportunities to our colleagues in other parts of the globe, by allowing anyone to view the content free of charge." \\ W. Jeffery Hurst, The Hershey Company. \\ - available free of charge to the entire scientific community \\ - peer reviewed and published immediately upon acceptance \\ - cited in PubMed and archived on PubMed Central \\ - yours - you keep the copyright \\ Submit your manuscript here: \\ http://www.chemistrycentral.com/manuscript/

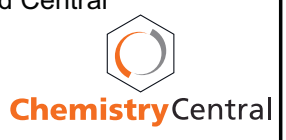

